\title{
TEKS POP DAN STUDI GENDER
}

\author{
Oleh: Widyastuti Purbani
}

\begin{abstract}
Abstrak:
Studi gender di Indonesia pada umumnya masih kurang bergerak di dataran ideologis. Apalagi yang menyangkut budaya massa. Meskipun pengkajian gender terhadap aparat-aparat ideologi (Althuser) sudah mulai dilakukan, studi mengenai karya dan teks pop masih belum digarap secara serius. Hal ini mungkin disebabkan masih kuatnya anggapan bahwa yang dikategorikan karya budaya adalah karya yang adiluhung dan serius semata.

Sementara itu karya pop memiliki sifat-sifat khusus yang membuat genre ini semakin problematis. Beberapa di antara sifat khusus tersebut adalah: pembaca atau penikmatnya bersifat massal, kuatnya pengaruh kepentingan bisnis dalam penciptaannya, formulasinya cenderung instant, potensinya besar untuk menyebarkan ideologi bawah sadar dan sekaligus untuk mengkonstruksi subjektivitas, termasuk di dalamnya subjektivitas gender.

Tulisan ini memaparkan beberapa argumen mengapa dengan demikian studi tentang karya dan teks pop perlu dilakukan secara serius dalam rangka memahami bahwa konsep serta subjektivitas gender masyarakat kebanyakan telah secara terus menerus terbentuk oleh teks-teks ini.
\end{abstract}

\section{A. Pendahuluan}

Pendapat yang menyatakan bahwa ketidakadilan gender telah dan masih berlangsung di Indonesia sejak berabad-abad diakui oleh beberapa pakar baik dari dalam maupun luar negeri, antara lain Berman (1993), Mariyah (1995), Balckburn (1995), Sugandhi (1996), Munandar (1996), Mansour Fakih (1996) dan Irwan Abdullah (1997). Munandar menggambarkan adanya kecenderungan bahwa di Indonesia wanita cerdas malu untuk berunjuk diri, karena dengan tampil terlampau 'intelligent' dikhawatirkan nilai kewanitaannya akan luntur. Banyak wanita merasa bangga akan predikatnya sebagai ibu rumah tangga, serta berpikir bahwa menjadi wanita yang mandiri dan berkarir dapat mengancam ketenteraman rumah-tangganya, yang dipercaya sebagai tanggung jawab utama kaum wanita tersebut (1996:3). Susan Blackburn (1995:17) menggambarkan bahwa kasus-kasus perkosaan, aborsi 
dan hukuman sosial yang berat terhadap wanita hamil di luar nikah telah menjadi hal yang dibiarkan berlangsung begitu saja di kalangan wanita Indonesia. Berman (1993:2) menyimpulkan bahwa mayoritas wanita Indonesia sudah merasa puas dengan predikatnya sebagai nomor dua dan bersedia untuk selalu mengalah dalam bentuk the glory of suffering atau pemuliaan pengorbanan. Data-data statistik bidang pendidikan, pekerjaan dan kepemimpinan di Indonesia cukup menggambarkan sangat dominannya kedudukan kaum laki-laki dibanding dengan kaum perempuan yang jumlahnya sama bahkan sedikit lebih besar (data-data BPS 1994).

Belakangan ini pembicaraan mengenai gender di Indonesia sudah semakin marak seiring dengan mulai bangkitnya kesadaran akan adanya ketidakadilan gender terhadap kaum perempuan, namun hasil yang tampak secara nyata masih belum begitu menggembirakan. Para pakar kemudian sepakat untuk menyimpulkan bahwa perjuangan memerangi ketidakadilan gender di Indonesia merupakan 'a long way to go' (Blackburn 1995) dan yang harus diupayakan terus menerus dalam berbagai cara.

Salah satu hal yang sesungguhnya sangat esensial untuk ditempuh, namun justeru masih diabaikan dalam pembicaraan gender, adalah memerangi ketidakadilan gender lewat aparat-aparat ideologi yang tumbuh pesat dalam masyarakat, termasuk di antaranya lewat cerita, berita mass-media baik yang tegolong the great text maupun yang dikategorikan 'pinggiran'. Kebanyakan analisis atau pengkajian berperspektif gender masih saja mengkonsentrasikan diri pada teks atau karya sastra dengan kapital S, atau karya-karya yang serius saja. Karya sastra pinggiran, termasuk teks pop belum mendapat perhatian secara serius, sedangkan bila dilihat dari magnitude-nya, justeru karya-karya pop inilah yang telah memiliki peran yang besar dalam rangka pembentukan konsep gender masyarakat luas.

Tulisan ini akan mengupas mengapa karya-karya pop perlu pula dibuka, dianalisis, diteliti dan dikaji secara mendalam mengenai unsur-unsur yang dikandung, struktur dan ideologinya, dan subject positioning-nya dalam kaitannya dengan studi gender di Indonesia.

\section{B. Budaya Merupakan Sesuatu yang Biasa}

Bahwa karya-karya serius umumnya menjadi pusat dan inti suatu 
pengkajian budaya sudah terjadi sejak lama di mana-mana. Selama berabadabad teks budaya hampir selalu dikaitkan dengan hal-hal yang bersifat 'adiluhung', milik kelompok orang tataran atas atau kaum borjuis. Orang kebanyakan atau common people secara tradisional terpinggirkan dari pembicaraan mengenai teks budaya. Keadaan seperti ini ditentang oleh Raymond Williams yang mengatakan bahwa '.to go on to say that working people are exluded from (English) culture is nonsense; they have their own growing institutions, and much of the strictly bourgeois culture they would in any case not want' (1993:9). Adalah suatu dosa besar untuk mengesampingkan karya dan karsa golongan menengah ke bawah karena sesungguhnya sebagian besar dari budaya bangsa ikut ditentukan oleh common meanings dan common institutions yang berakar dari orang kebanyakan. 'A great part of the way of life, and of its arts and learning, is not bourgeois (9). Sebagian terbesar dari kehidupan, seni dan pembelajaran bukanlah bersifat borjuis. Dalam banyak hal kita temukan lembaga-lembaga dan common meanings yang juga merupakan inti dari suatu kebudayaan. Memperkuat apa yang dikatakannya di atas, Williams menyatakan pula bahwa menganggap budaya sebagai sesuatu yang ekslusif dan khusus tidaklah tepat. Budaya adalah sesuatu yang biasa:

Culture is ordinary: that is the first fact. Every human society has its own shape, its own purposes, its own meanings. Every human society expresses these, in institutions, and in arts and learning. The making of a society is the finding of common meanings and directions, and its growth is an active debate and amendment under the pressures of experience, contact and discovery, writing themselves into the land......The questions I ask about our culture are questions about general and common purposes, yet also questions about deep personal meanings. Culture is ordinary, in every society and in every mind (6).

Pada intinya, budaya adalah hal yang biasa, kebanyakan (bukan spesial atau istimewa), yang menyangkut keseharian hidup manusia-manusia anggota komunitasnya. Seluruh individu dalam komunitas budaya ikut 
berperan menciptakan dan mengekspresikan budaya dalam lembaga, seni dan pembelajaran. Penciptaan budaya adalah juga pencarian makna dan arah dari common meanings. Perdebatan mengenai budaya haruslah ikut serta menjawab common meanings.

Teks pop adalah common meanings dan sekaligus adalah common questions, hal-hal yang menyangkut cipta, rasa dan selera orang kebanyakan atau common people, atau yang oleh John Fiske disebut kaum 'subordinat' dan 'lemahkuasa' :

Popular culture is made by various formations of subordinated or disempowered people out of the resources, both discursive and material, that are provided by the social system that disempowered them. It is therefore contradictory and conflictual to its core (1989: 1).

Karya pop dibentuk oleh berbagai formasi kaum subordinate atau kaum tak berkuasa. Karena keberadaannya yang tidak mungkin terhenti dalam ikut serta membentuk budaya manusia, pencarian makna terhadap teks pop merupakan tugas dan tanggung jawab para pelaku budaya tersebut.

\section{Karya Pop, Karya Pabrikan dan Budaya Instant}

Produk budaya pop, karena sifatnya sebagai komoditi massal yang 'fabricated by the technicians hired by the businessman' (Macdonald: 1994:30), rata-rata tidak atau kurang digarap untuk kepentingan serious art, dan umumnya hanya berintikan desire dan pleasure (hal yang bersifat keinginan dan kesenangan). Para pekerja teks pop sesungguhnya lebih tertarik pada uang yang akan diperoleh dari hasil karyanya daripada arti produknya bagi kepentingan kehidupan manusia.

Teks seperti termaksud di atas pada umumnya memposisikan pembaca/penonton sebagai konsumer pasif yang partisipasinya terbatas pada pilihan 'membeli' atau 'tak membeli' (Macdonald: 1994:30) dan bukannya melakukan pemikiran kritis. Menurut Clement Greenberg dalam Macdonald, pekerja teks pop yang umumnya ditunggangi kepentingan bisnis dan dimudahkan oleh teknologi, cenderung 'predigests art for the spectator and spares him effort, provides him with a shortcut to the pleasures of art' (31). 
Kemudahan teknologi telah mendorong pekerja karya pop untuk melakukan 'pengunyahan' awal dan membantu memberi jalan pintas menuju kesenangan yang dicari di dalam seni. 'Pengunyahan' seni atau 'peracikan' seni menjadi siap 'telan' demi kepentingan pleasure atau kesenangan inilah yang kemungkinan telah membuat teks pop sangat mudah dikonsumsi dan oleh karenanya sering cenderung mengalami pendangkalan. Pembaca atau penikmat sudah diberi reaksi yang melekat di dalam teks, sehingga tidak perlu harus bersusah payah melakukan respons sendiri, apalagi melakukan pemikiran kritis. Karena formulasinya yang instant dan mudah dicerna tadi, maka teks pop diduga mempunyai kecenderungan untuk memuat ideologi yang dangkal pula. Kekhawatiran yang muncul kemudian adalah pembaca akan terbawa untuk memiliki pemikiran yang dangkal serta malas melakukan respons. Halhal inilah yang kemudian membuat karya pop semakin bermasalah bagi pembaca yang bersifat massal, dan yang umumnya merupakan working class people itu.

Setiap teks memiliki ideologi tertentu. Teks-teks dalam karya pop, seperti juga teks serius, sangat potensial untuk menyebarkan ideologi bawah sadar atau unconscious/concealed ideology (Hollindale 1983). Menurut sifatnya, unconscious ideology merupakan ideologi yang penyusupannya atau interpelasinya (Althuser) lebih intens, namun kurang dirasakan oleh pembaca atau penonton sebagai penikmat. Sementara itu, bila telah menyusup, unconscious ideology akan cenderung lebih merasuk, tertanam dalam hati penonton (audiences) dan bertahan relatif lebih lama (Stephens, 1992). Karena proses merasuk yang perlahan dan dengan cara yang relatif lebih halus, kemungkinan terjadi penolakan dan pengkajian kritis terhadap ideologi yang dikandung cenderung lebih kecil. Oleh karena itu, keberadaan dan peran ideologi bawah sadar tidak boleh tidak harus diwaspadai secara lebih serius (Hollindale, 1983:3).

Tanggung jawab untuk menempatkan teks pop sebagai salah satu pelaku pembentuk budaya (culture maker), serta adanya sifat-sifat khusus teks pop yang membuatnya problematik seperti tersebut di atas, mestinya memacu dilakukannya penelaahan serta penelitian karya/teks pop sebanyak mungkin. Seperti penegasan Siregar (1997:146) yang pernah dinyatakan Yacob Sumarjo (1995): Karenanya studi tentang budaya massa menjadi penting mengingat besaran (magnitude)-nya dalam masyarakat. 


\section{Karya Pop dan Studi Gender}

Maskulinitas dan femininitas menurut Davies bukanlah kodrat atau fitrah manusia, namun merupakan: “......inherent or structural properties of our society: that is, they both condition and arise from social action. Each of us as a member of society, takes on board as our own the 'knowledge' of sex and of gender as they are socially constituted" (1989:13). Maskulinitas dan femininitas dibentuk atau dikonstruksi oleh piranti sosial yang hidup dalam masyarakat. Subjektivitas terhadap femininitas dan maskulinitas merupakan hasil dari jaringan diskursus yang mengelola dan mensistem praktik-praktik sosial budaya. Subjektivitas yang dimaksud tidaklah fixed atau tetap namun selalu dalam proses pembentukan kembali/rekonstruksi yang tak pernah berhenti melalui interaksi sosial yang dilakukan seseorang dalam kehidupan sehari-hari (Davies 1993: 111).

Sementara itu Christ Weedon, tokoh feminisme dalam dunia sastra dan budaya, menyatakan bahwa language atau bahasa merupakan 'the place where actual and possible forms of social organisation and their likely social and political consequences are defined and contested...... our subjectivity, is constructed (Weedon, 1987:21). Bahasa merupakan arena atau situs di mana bentuk dan organisasi sosial serta konsekuensi sosial politik masyarakat didefinisikan, serta sense tentang diri serta subjektivitas kita dibentuk atau dikonstruksi.

Terry Eagleton menegaskan bahwa 'language is power, conflict and struggle weapon as much as medium, poison as well as cure, the bars of the prison house as well as a possible way out' (1985:5). Dan bagi Stephen bahasa adalah situs bagi dampak-dampak ideologis yang memiliki kekuatan yang besar untuk membentuk perilaku pembacanya. 'language is a special site for ideological effect, with potentially powerful capacity for shaping audiences' attitudes' (1992:3).

Telas bahwa kekuatan bahasa amat dahsyat dalam membentuk opini dan atau subjektivitas masyarakat pembacanya, dan salah satu bentuk subjektivitas yang dimaksud adalah subjektivitas tentang diri dan gender. Seperti yang juga dikatakan oleh Saussure dalam Weedon 1987 bahwa makna 'perempuan' atau kualitas yang melekat pada kata 'perempuan' telah diproduksi oleh dan melalui bahasa atau teks (23). 
Teks-teks pop mengandung dua inti tak terpisahkan, yakni berita/pesan dan bahasa. Dan bahasa memiliki kekuatan yang amat besar dalam membentuk atau mengkonstruksi subjektivitas atau opini publik. Tidak dapat diragukan lagi bahwa konsep gender yang berlaku dalam masyarakat Indonesia sekarang ini-pun telah dibentuk selama berabad-abad lewat teks-teks yang ada dalam diskursus yang ada, dan salah-satu teks tersebut adalah yang diproduksi oleh teks-teks pop. Seperti argumen Pam Morris bahwa 'what we consider to be 'manly' may derives as much from the way in which masculinity is imagined for us in stories, picture and the media (1993:8) maka teks pop telah dan akan terus menerus membentuk subjektivitas gender pembaca/penontonnya yang pada umumnya adalah kaum perempuan sendiri, termasuk di dalamnya kaum remaja penerus generasi bangsa.

Bahwa karya pop kemudian menjadi sangat potensial untuk memotret serta melihat ideologi gender masyarakat ditegaskan oleh Dorothy Smith:

To examine the discourse of femininity is to examine the organization of relations among the mass media of women's magazines, advertising, television and movie images, and romance imaging, imagining, and enunciating femininity; the productive and commercial organization of fashion, cosmetic, and garment industries; and women's but also men's local practices in their everyday worlds (1998:53).

Menurut Smith ideologi serta doktrin femininitas telah disiarkan secara luas melalui citra dan imagi yang terkandung dalam diskursus yang secara komersial diproduksi oleh karya-karya pop semacam majalah, iklan, televisi serta film-film (43).

\section{E. Penutup}

Untuk mencapai kesetaraan gender yang diidam-idamkan oleh masyarakat Indonesia, yang masih mengisyaratkan jalan yang panjang, studi gender yang bergerak di dataran ideologis, terutama yang menyangkut masyarakat kebanyakan penting sekali untuk dilakukan secara serius. Karya atau teks pop merupakan karya yang menyangkut masyarakat kebanyakan yang bersifat mass. Teks jenis ini juga memiliki peluang yang besar untuk 
membentuk subjektivitas masyarakat serta untuk menebarkan ideologi bawah sadar. Sifat-sifat teks ini yang umumnya ditunggangi kepentingan bisnis sehingga hasilnya merupakan karya formula dan bersifat instant, membuatnya semakin problematis. Pembaca teks pop, bila dibiarkan begitu saja menelan teks-teks instant tanpa diberi suatu guidance untuk menyeleksi maupun memberi makna alternatif, akan dibentuk oleh teks pop untuk memiliki pemikiran yang dangkal pula.

Subjektivitas gender tidak akan pernah lepas dari konteks yang serupa. Ia dibentuk dan akan selalu dibentuk oleh teks-teks pop yang hidup dalam masyarakat. Kealpaan untuk melakukan studi dan analisis terhadap karya-karya pop ini akan lebih melestarikan ketidakadilan gender yang masih terus mengancam kaum jelata, kaum pekerja sebagai konsumen terbesar karya-karya ini.

\section{DAFTAR PUSTAKA}

Abdullah (1997) Sangkan Paran Gender. PPK UGM, Yogyakarta

Althusser, Louis (1991) “Ideology and Ideological Apparatuses" dalam Ideology h. 50-56

Berman, Laine (1993) "On the Javanese Women", makalah disampaikan pada Seminar tentang Wanita Indonesia, Unibraw, Malang

Biro Pusat Statistik (1994) Buku Statistik Indonesia 1994, CV Indonesia, Jakarta

Blackburn, Susan (1995) “A long way to go" dalam Inside Indonesia, Edisi Maret 1995 hal 17-18

Bronwyn, Davies (1993) "The sense children make of feminist stories" dalam Readings in Literary Literacy, Deakin University Press, Melbourne hal 49-68

Eagleton, Terry (1991) 'What is Ideology' dalam Ideology: An Introduction, hal $1-30$ 
Eagleton, Terry (1983) Literary Theory. Blackwell, Oxford

Eco Umberto (1985) The Role of the Reader, Indiana University Press, Bloomington

Fakih, Mansour (1997) Analisis Gender dan Transformasi Sosial, Pustaka Pelajar, Yogyakarta

Faruk (1994) Pengantar Sosiologi Sastra, Pustaka Pelajar, Yogyakarta

Fiske, John (1989) "Understanding Pop Culture" dalam Reading the Popular hal 1-13 oleh Fiske

Fiske, John (1982) Introduction to Communication Studies, Routledge, New York

Hardiyanta, Peter Sunu (1997) Michel Foucault: Disiplin Tubuh, Bengkel Individu Modern, LKIS, Yogyakarta

Gilbert, Pam and Taylor, Sandra (1991) Fashioning the Feminine: Girls, Pop Culture and Schooling, Allen \& Uwin, Sydney, Australia

Hollindale, Peter (1988) "Ideology and Children's Book" dalam Signal 55, 1988 hal 3-22

Hutcheon, Linda (1988) A Poetic of Postmodernism. Routledge, London

Krippendorff, Klaus (1993) Analisis Isi: Pengantar Teori dan Metodologi, Raja Grafindo Persada, Jakarta

Mariyah, Chusnul (1995) "Gender and Patriarchy in Indonesian Politics" dalam Inside Indonesia, Edisi Maret 1995

Macdonald, Dwight (1994) “A Theory of Mass Culture" dalam Cultural 
Theory and Popular Culture oleh John Storey 1994, University Press, Cambridge

Morris, Pam (1993) Literature and Feminism. Blackwell, Oxford

Munandar, Utami (1996) "Kemitrasejajaran Pria dan Wanita" makalah disampaikan dalam Seminar tentang Kemitrasejajaran, Sentra Grafika, Yogyakarta

Purbani, Widyastuti (1996) “Gender Ideology in Bobo Stories”, Thesis S2, Deakin University, Melbourne

Nicholson, Linda J (1990) Feminism/Postmodernism, Routledge, London

Shiach, Morag (1991) "Feminism and Popular Culture" dalam Cultural Theory and Popular Culture oleh John Storey 1994, University Press, Cambridge

Siregar, Ashadi (1997) "Budaya Massa: Sebuah Catatan Konseptual Tentang Produk Budaya dan Hiburan Massa" dalam SENI: Jurnal Pengetahuan dan Penciptaan Seni Vol 03-04 Juli 1997, BP ISI, Yogyakarta

Smith, Dorothy (1988) "Femininity as Discourse" dalam Becoming Feminine: The Politics of Popular Culture, The Falmer Press, London

Stephens, John (1992) Language and Ideology in Children's Fiction, Longman, London

Sugandhi, Mien (1996) "Meningkatkan Kemitrasejajaran Pria dan Wanita" " makalah disampaikan dalam Seminar tentang Kemitrasejajaran, Sentra Grafika, Yogyakarta torey, John (1994) Cultural Theory and Popular Culture (A reader). Harvester, New York 
Sumaryono (1993) Hermeneutik. Penerbit Kanisius, Yogyakarta

Weedon, Christ (1987) Feminist Practice and Poststructuralist Theory. Basil, Blackwell Inc., Cambridge

Williams, Raymond (1989) "Culture is Ordinary" dalam Studying Culture: An Introductory Reader oleh Gray, Ann (ed) 1993, Edward Arnold, London 